\title{
MIRADA SOBRE EL JOVEN BARRISTA Y LA CONVIVENCIA CIUDADANA
}

\section{LOOK ON YOUNG “BARRISTA” AND CITY COEXISTENCE}

\author{
Víctor Hugo Durán ${ }^{1}$ \\ Ramiro Andrés Alzate ${ }^{2}$ \\ Sergio Martínez ${ }^{3}$
}

\section{Resumen}

El presente escrito socializa los resultados de la intervención realizada por los autores en la ciudad de Bogotá, financiada por la alcaldía local de Bosa en el marco del proyecto denominado Prevención de los Conflictos Urbanos, la Violencia y el Delito. Este trabajo da cuenta de la situación actual de la juventud barrista en esta zona de la capital colombiana, y describe de manera global lo que significa ser barrista y su relación con el interior del colectivo y del entorno social. Los datos se recogieron a partir de encuestas semiestructuradas, talleres de reconocimiento, acompañamiento a la intervención de espacios comunitarios y revisión documental relacionada con el fenómeno del barrismo a nivel distrital. De igual forma, se contó con el apoyo de barristas, miembros de la comunidad y gestores de la localidad, quienes sirvieron de enlace con el grupo de jóvenes barristas. El proceso hizo evidente la poca información que se tiene con respecto a la juventud barrista desde ópticas diversas, positivas e incluyentes, que den apertura al reconocimiento del otro y a generar procesos de participación verdadera en la comunidad, que transforme la visión estigmatizada sobre el joven y sus prácticas así como la postura asistencialista de los gobiernos locales.

Palabras claves: barrismo; jóvenes; convivencia

\section{Abstract}

The present paper socializes the results from the intervention developed by the authors in Bogota, and sponsored by the Bosa's Local District Mayor on a Project called: "Prevention of Urban Conflict, Violence, and Crime". This article accounts for the current situation of young fans in this area of the Colombian capital and describes what it means to be one and their relationship within the group and with the social environment. Data were collected from semi-structured surveys, examination workshops, and the accompaniment of the intervention of the community's spaces and the documentary review related to the phenomenon of barrismo at a district level. For this, the researchers had the support of barristas' community members and local managers, who served as liaison with the group of young barristas. This process reveled the few information available regarding the barristas youth from diverse, positive and inclusive points of view that allow the recognition of the other and generate processes of real participation in the community, in order to transform the stigmatized vision of the young, their practices and the local governments' welfarist position.

Keywords: barrismo; young; coexistence

Fecha de recepción: 20 de octubre de 2015

Fecha de aprobación: 3 de marzo de 2016

Para citar este artículo:

Durán, V. H., Alzate, R. A. y Martínez, S. (2016). Mirada sobre el joven barrista y la convivencia ciudadana. Lúdica Pedagógica, (23), 31-42.

1 Doctorando en Educación, Universidad Pedagógica Nacional, docente ocasional tiempo completo Facultad de Educación Física. Correo electrónico: guajiro78@gmail.com

2 Magíster en Educación, Universidad Pedagógica Nacional, asesor convenido Universidad Pedagógica-Secretaría de Educación Distrital. Correo electrónico: ramironcho@gmail.com

3 Psicólogo, Universidad de la Sabana, psicólogo educativo, organizacional y social-comunitario. Correo electrónico: sergiomartinez79@gmail.com 


\section{INTRODUCCIÓN}

En el marco del proyecto Prevención de los Conflictos Urbanos, la Violencia y el Delito se realizaron actividades de aproximación con los jóvenes barristas de una localidad de Bogotá, la intención y esfuerzos se dirigieron a generar lazos entre las instituciones públicas y este colectivo de jóvenes, como base para la obtención de información y proyección acciones futuras en términos de política local.

Adicionalmente, y a solicitud de la alcaldía local, se da cuenta de la situación actual de la juventud barrista en esta zona de la capital colombiana, se generan estadísticas, marcos de referencia y descripción global de lo que para los participantes significa ser barrista, así como las relaciones que se establecen al interior del entorno social de dicho colectivo de jóvenes.

Entre las pretensiones del gobierno local también se encuentra: 1. Dar emprendimiento a jóvenes pertenecientes a núcleos familiares y/o cinco organizaciones de jóvenes vinculados a los conflictos de la localidad. 2. Implementar los planes de negocio y proyectos productivos. 3. Visualizar el trabajo de jóvenes pertenecientes a organizaciones vinculados al conflicto y/o que hagan parte de organizaciones de unidades productivas de la localidad. Y 4. Promover acciones integrales mediante acuerdos interinstitucionales que hagan parte efectiva para el fortalecimiento educativo, cultural, deportivo, salud, ambientales, artísticas de bienestar y productivo de organizaciones de jóvenes vinculados a los conflicto.

Fue una condición, por parte de los gestores del proyecto, aproximarse a los jóvenes barristas y sus realidades desde el reconocimiento de las mismas; con el propósito de enriquecer la visión que popularmente se tiene sobre sus acciones y ahondar en lo que las sustenta

A partir de esta premisa, surge la necesidad de reconocer a los jóvenes como sujetos de derechos en condiciones de equidad, constructores de representaciones diversas de realidad basadas en condiciones de territorialidad, trans-sectorialidad, integralidad y autonomía.

Se hace entonces indispensable y de vital importancia para la alcaldía local que a través de este proyecto se potencie la visión de y sobre los jóvenes como "sujetos de derechos, en su doble significación de construcción de condiciones para el ejercicio pleno de la ciudadanía y del establecimiento de garantías sociales e institucio- nales para el respeto y cumplimiento de sus derechos fundamentales". Por lo tanto, el proyecto se justifica en tanto que se propicien los espacios de encuentro entre los participantes y la comunidad.

Por otra parte, y en referencia al impacto que busca generar este proyecto en la comunidad a la que se dirige, contó con la participación de cien jóvenes presentes en las diferentes actividades propuestas por la alcaldía local como son:

- Talleres de capacitación

- Intervención de espacios comunitarios

- Recolección de información a través de encuestas semiestructuradas

- Presentación de proyectos de emprendimiento

- Organización y participación en eventos deportivos

Lo anterior se reitera en la generación de oportunidades para el encuentro entre los jóvenes barristas, la comunidad y las instituciones del gobierno local, la estrategia a implementar para alcanzar los objetivos propuestos establece tres momentos diferentes durante el desarrollo del proceso que se describen a continuación:

Recolección de información y convocatoria, con el apoyo de los gestores y líderes de las diferentes barras juveniles, de la que resultó una base de datos para las reuniones de acercamiento a las que haya lugar.

Actividades de formación, capacitación sobre emprendimiento, intervención de espacios comunitarios, generación de encuentros entre grupos (mesa futbolera), recolección de información (entrevista semiestructurada) y organización de torneos deportivos.

Revisión de la información y descripción situacional, para generar el presente informe descriptivo y prospectivo.

Un aspecto fundamental de la propuesta es el reconocimiento de los múltiples actores y sus importantes funciones, entre ellos se resalta la participación de los líderes de la comunidad que han sido elegidos como jueces de paz y de reconsideración o que han recibido formación como mediadores, conciliadores en equidad o promotores para la resolución pacífica de conflictos.

El proyecto estableció específicamente que estos actores intervendrán en el desarrollo del mismo según los siguientes criterios: 1 . Apoyo en el proceso de convocatoria 
de todos las actividades del proyecto. 2. Participación activa en las actividades del proyecto. 3. Cooperación continúa en el aspecto organizativo de cada actividad. 4. Veedurías y 5. Transmisión de contenidos técnicos.

\section{ANTECEDENTES}

Las barras y los jóvenes ¿fenómeno de conflicto o violencia?

Al realizar una revisión documental sobre los antecedentes históricos de la aparición de las barras como alternativas de filiación, es difícil lograr un consenso que explique esta realidad, entendiendo incluso que los orígenes pueden ser considerados como un punto de controversia dada su difícil ubicación en el tiempo y el espacio. No obstante, se pueden resaltar algunos elementos de convergencia para explicar las dinámicas actuales de estos grupos, como por ejemplo:

- No se puede hacer una generalización entre los actores inmersos en hechos violentos en torno al fútbol profesional y la condición de ser barrista.

- Es evidente que las manifestaciones de las barras en Colombia se han visto influenciadas por modelos extranjeros de agremiaciones deportivas, que se manifiestan de manera violenta en sus contextos particulares.

- Al igual que otras esferas de los sectores colombianos, el deporte fue permeado por fenómenos sociales, culturales, políticos y económicos del país.

- Los contextos afectados por fenómenos sociales de inequidad, exclusión, escasa educación, pobreza y falta de oportunidades son proclives a situaciones y manifestaciones de violencia e intolerancia.

La revisión de la literatura encontrada nos muestran distintas posturas sobre las barras y la juventud barrista; sin embargo, una recurrencia es la aproximación a esta temática desde su asociación con "la violencia" o con los hechos violentos. Pareciera ser que sin los hechos concretos de violencia, tanto estas agremiaciones, sus actividades y sus manifestaciones identitarias, así como la comprensión de la juventud y su vínculo con las problemáticas sociales que afectan al país, no fueran importantes.
Por lo mismo, se abre una ventana para pensar y explorar la realidad de estos actores, relaciones y manifestaciones, desde otra óptica, como procesos de resistencia ante un contexto adverso que se caracteriza por la falta de oportunidades en cuanto a educación, proyección laboral y desarrollo socio-cultural, etc.

No obstante, tampoco hay que perder de vista la violencia y los factores asociados a la misma, pues, como se ha mencionado, todo ello hace parte de una trama social compleja en la cual el joven y, en este caso específico, el joven barrista también se encuentra inmerso, pues según la ponencia denominada "La violencia en el espectáculo del fútbol, una realidad en el nuevo contexto colombiano", presentada por Jesús Eduardo Vélez Mejía en el X Congreso Mundial de Historia del Deporte, se constituye en "la nueva forma de violencia en Colombia":

Los colombianos son los responsables del $30 \%$ de las muertes violentas en América Latina. Homicidios, secuestros, asesinatos políticos, lesiones fatales por diferentes causas, accidentes de tránsito, violencia intrafamiliar, desapariciones forzadas, violencia contra la mujer y los niños, son algunas de las formas con las que a diario se presenta la violencia en nuestro país, y ahora, para terminar de completar la nueva y nefasta historia de violencia en el Fútbol y el deporte espectáculo. (Vélez, 2005, p. 2)

Los hechos violentos que la historia relata asociados al fútbol profesional han ido transformando la manera de ver el deporte y todas las dinámicas asociadas a él, al igual que las connotaciones frente al "hincha": "Aficionados que encuentran en el estadio el lugar natural de la brutalidad, el mal trato y el irrespeto; el periodista y el comentarista deportivo con su pasión e intereses económicos" (Vélez, 2005, p. 4).

Sin embargo, la violencia en el deporte es una manifestación que se viene estudiando desde los tiempos de los romanos; en ese sentido, el colombiano no ha sido ajeno a este tipo de manifestaciones que muchas veces se ven permeadas por la realidad y el contexto social del país.

En la búsqueda de los orígenes de estos fenómenos de violencia en los escenarios deportivos, tratamos de hacer un rastreo para identificar en el tiempo el momento exacto en el que se organizan estos grupos sociales llamados barras.

El fenómeno de las barras ha sido una relación que ha nacido casi al mismo tiempo que el espectáculo del fútbol en Colombia, la denominada época de "el dorado" 
que es conocida como el periodo en el cual llega el fútbol de manera profesional al país y aparece un sentido de filiación con determinados equipos de acuerdo al contexto regional o al grupo social que representa. Vélez, acerca de los orígenes del barrismo en el país, nos dice:

Muchachos y niñas de todos los estratos sociales y económicos de la ciudad, unidos solo por una insignia, un color, una pasión, una razón y un sentimiento, para ver y disfrutar los encuentros futboleros. En Colombia las ciudades empiezan a llenarse de grafitis y simbología entre barras, la cultura de la camiseta o insignia de la escuadra futbolera preferida o de la región, adquieren estatus. Las banderas inundan los escenarios deportivos y se da un relevo generacional al interior del estadio. (2005, p. 3).

Algunos estudios, como el de Clavijo (2004), ubican el barrismo como un fenómeno de las décadas de los cincuenta, cuando los hinchas comenzaban a agruparse en asociaciones barriales entorno al acompañamiento a los equipos bogotanos con el objetivo de alentar al equipo con el que se sentía identificados.

Por otra parte, las hinchadas bravas del fútbol son parte del espectáculo, pero no representan la realidad, ni el contexto del barrismo en nuestro país, en este contexto se podrían definir como una versión criolla y tercer mundista de los hooligans ingleses y una copia foránea de las torcidas brasileras y argentinas, las que se han constituido en el referente más inmediato de los grupos de barras bravas en Colombia. Los hooligans se podrían catalogar como el resultado de la transformación paulatina del fútbol en espectáculo cautivador de grandes masas a nivel mundial, que despierta todo tipo de pasiones y mueve diferentes tipos de intereses, los cuales, como lo menciona Vélez (2005), unidos al nuevo mundo globalizado, permitieron impulsar a nivel mundial y en especial en algunos lugares del planeta, una forma de expresión por demás violenta.

El fenómeno de la barras bravas en Colombia, como lo documentan algunos estudios Ávila (2008), Clavijo (2004), Vélez (2005), entre otros, se ubica a finales de los años 80 y principios de los años 90, cuando nace la rivalidad entre los equipos de Bogotá, Medellín y Cali, y se pasa de una manera pasiva de ver el fútbol a una forma activa y diferente. La primera barra brava, según algunos autores, tiene sus orígenes en la cuidad de Bogotá, se llamó Blue Rain, la cual se convirtió después en los Comandos Azules \# 13, del equipo Los Millonarios; luego aparece la guardia albirroja sur del Santa Fe también en la cuidad de Bogotá. Los del Sur en Medellín fieles a Nacional, Barón Rojo del América de Cali, hasta el punto que hoy casi la totalidad de equipos profesionales tienen al menos una barra brava (Clavijo, 2004).

La atención sobre estos grupos surgió de los problemas de seguridad en los que se ven involucrados los jóvenes de manera irregular, pero con relativa frecuencia. $\mathrm{Su}$ novedad como fenómeno social y la explosiva mezcla de problemáticas juveniles que condensan, aunque reconocido por muchos observadores, no ha desempeñado más que un papel marginal en la atención sobre las barras (Aponte, Pinzón y Vargas, 2009).

Lo anterior, asociado a hechos violentos difundidos a través de distintos medios de comunicación, fracturó la imagen de las barras y ayudó a que la sociedad en general generalizara y asociara el deporte y los jóvenes como fuente de disturbios

Las frecuentes situaciones que por enfrentamientos entre barras se presentan, hacen de la violencia un elemento determinante en la dinámica de estas. En Colombia estos enfrentamientos han cobrado la vida de varios jóvenes integrantes de las barras. A continuación se referencian algunos hechos asociados a la violencia en los estadios en Colombia:

- 11 de Octubre de 1981. 4 muertos y 31 heridos en el estadio Alfonso López de Bucaramanga, después de protestas contra el árbitro. La policía dispara al aire.

- 17 de noviembre de 2002. Hincha del Atlético Nacional es apuñalado en el estadio Pascual Guerrero de Cali durante un partido entre el América y el Nacional.

- 7 de septiembre de 2003. Enfrentamiento en las tribunas del Pascual Guerrero entre seguidores del América y el Nacional deja 5 heridos.

- 2 de mayo de 2004. Un hincha del Junior muere en hechos confusos con la policía.

- 2004. Un hincha del América apuñala a otro del mismo equipo en el Pascual Guerrero.

- 23 de junio de 2008. Asesinato de un barrista del Cali por Barristas del Santafé, en la carretera que une a Bogotá con Cali. Entre otras referencias similares. (Gómez, s. f., p. 7). 
Por otra parte, el desarrollo de estos hechos de violencia ha ocasionado que la mirada institucional sobre los jóvenes y sus estructuras de organización como los "parches" se vean con gran preocupación y en muchos casos se relacionen con la conformación de estructuras delictivas, como son las pandillas juveniles.

No obstante, los grupos conformados como barras tienen una razón que a su vez funciona como primer referente identitario, determinado por la afición a un equipo de fútbol profesional, que posteriormente encuentra arraigo en un sitio particular del barrio.

Son cinco las barras bravas en Bogotá: la que apoya a Millonarios se llama Comandos Azules D.C.; a Santafé, Guardia Albirroja; al América de Cali, Disturbio Rojo; al Nacional de Medellín, los del Sur; y al Deportivo Cali, el Frente Radical Verdiblanco. Toda barra brava es la unión de secciones; cada sección es la suma de grupos de amigos; y cada grupo de amigos recibe el nombre de parche, que son reconocidos por los demás con un título: puede ser parche 1 , parche $2 . . .$, o por el apodo de un personaje llamativo en el grupo: el parche de el Calvo..., el parche de Mil manillas, etc. (Ávila, 2008, p. 6).

En el caso específico de los barristas que participaron del proyecto, reciben nombres como "Gaminería", seguidores del Atlético Nacional; "La academia" seguidores del Independiente Santa fe, que agrupa jóvenes pertenecientes a los barrios Brasil, Atalayas, Ciudadela el Recreo y Santa Fe entre otros; barra "La 73" también seguidores del Santa fe, la cual agrupa jóvenes provenientes de los barrios Laureles, Palestina, Carlos Albán y La Esperanza; "La Alameda" barristas del Atlético Nacional y habitantes de los barrios Laureles, Palestina, Carlos Albán y La Esperanza; y "Los Ramones", habitantes de los barrios San Pablo y La Amistad seguidores del equipo Atlético Millonarios, entre otras barras.

\section{Contextualización y territorialización}

Gran parte de las características y condiciones de las barras futboleras se sustentan en las dinámicas contextuales y territoriales de carácter histórico, socio-cultural y económico que determinan culturas internas de las localidades y barrios.

Muchos de estos barrios muestran históricamente una tradición indígena o campesina y estuvieron inmersos en un proceso de asentamiento continuo que desembocó en una rápida densificación, a lo cual se sumó la permanente migración de personas provenientes de municipios cercanos y familias de escasos recursos oriundas de otros lugares y que, en respuesta al bajo costo de la tierra en las zonas periféricas, llegaron con la esperanza de adquirir vivienda propia.

Sin embargo, el crecimiento paulatino de la localidad, de igual manera, el aumento de la población que lo habita, generó expectativas por las condiciones de calidad de vida de sus habitantes, que se encuentran directamente relacionada con las políticas de ordenamiento territorial, inversión y bienestar social.

Esto significa que en el lapso de tan solo 10 años la población local se elevó en un 280 \% que junto a otras problemáticas sociales del país, como es el desplazamiento forzado por la violencia y las migraciones internas, agudizaron las problemáticas de estos contextos, que no siempre son consecuentes con la activación de una respuesta social de igual importancia para garantizar el acceso a los servicios básicos de educación, salud, recreación, transporte, entre otras obras y servicios.

El DANE estima la pobreza a partir de una sumatoria de elementos que satisfacen las necesidades básicas de una persona en cuanto a alimentación, vestuario, educación, salud, cultura y otros. Estima la pobreza a partir del ingreso necesario para adquirir una canasta de alimentos que le permita a una persona satisfacer los requerimientos mínimos de calorías, proteínas y otros nutrientes necesarios para subsistir. (Cámara de Comercio de Bogotá, 2001, s.p.).

Con base en estos criterios se puede afirmar que el contexto del barrista se caracteriza por un alto porcentaje de personas en situación de pobreza y otras en situación de miseria, algunas cifras distritales hablan de un aproximado de 72000 en el primer caso y 11480 en el segundo desde el año 2001 y en aumento. Es importante precisar que en la localidad intervenida, los niños entre 0 a 5 años y las mujeres entre los 15 y 49 años se catalogan como las poblaciones más pobres y en miseria.

Frente a los índices de necesidades básicas insatisfechas, estratificación, morbilidad y mortalidad, desempleo y analfabetismo, las cifras tienen un comportamiento similar, esta localidad presenta un índice por encima de la media en la ciudad de Bogotá.

Por lo tanto, sin pretender una mirada pesimista al respecto, tenemos una localidad muy densamente poblada, con un sinnúmero de fenómenos sociales relacionados 
con la pobreza, el desempleo y desplazamiento, los cuales se manifiestan a través de problemáticas internas que se ven reflejadas en: familias desestructuradas, deserción escolar, explosión demográfica, población flotante, problemas sanitarios y brotes de violencia infantil, de género, discriminatoria, entre otras.

\section{METOdOLOGÍA}

En atención a los objetivos del proyecto, se planteó una caracterización de los jóvenes inmersos en las barras de una localidad en la ciudad de Bogotá; se trató de ofrecer una mirada interpretativa, es decir, centrada en la perspectiva de los gestores sin pretender emitir juicios de valor o calificativos sobre sus realidades, ubicarlos como miembros de una comunidad influenciada por fenómenos sociales y, al mismo tiempo, como seres humanos y ciudadanos sujetos de derecho.

De las diferentes características abarcadas durante la realización del proyecto, se destacan las relacionadas con la identidad de los miembros de las barras, la relevancia que alcanza el género y las circunstancias humanas como condición de pertenencia al grupo, la construcción y complejidad de símbolos, significados y discursos en el barrismo, así como, las relaciones entre identidad y territorio, vínculos de sus integrantes con estructuras sociales formales o instituciones (familia, autoridades, educación, gobierno local).

Para la recolección de la información a mencionar se utilizaron como instrumentos: a) encuesta escrita semiestructurada con preguntas abiertas y de opción múltiple; b) taller de reconocimiento con jóvenes barristas para explorar las relaciones, significados y percepciones de los jóvenes barristas y su comunidad; c) acompañamiento a la intervención de espacios comunitarios, en el que dos gestores realizaron su observación participante en una actividad colectiva de los distintos grupos barristas (pintura y mejoramiento de parques y espacios recreativos), y d) revisión documental relacionada con el fenómeno del barrismo en Bogotá y la localidad en específico (periódicos, artículos, investigaciones, videos, entrevistas, documentales, proyectos, etc.).

En cuanto a la estrategia para la aplicación de dichos instrumentos, se contó con el apoyo de barristas, miembros de la comunidad y gestores de la localidad, quienes sirvieron de contacto con el grupo de jóvenes, al mismo tiempo ofrecieron su conocimiento de los mismos para convocarlos a las actividades de intervención de espacios y taller, con la autorización, conocimiento y aporte voluntario los barristas diligenciaron la encuesta semiestructurada.

\section{HALLAZGOS}

Referentes simbólicos, significados y discursos

A lo largo de su ciclo vital, los seres humanos reconocen que están inmersos en un mundo diverso, encuentran su lugar en el mismo y desarrollan formas de interpretar todo los que los rodea, mientras intentan comprender lo que son y lo que hacen; de todos estos procesos complejos resultan esquemas mentales, referentes simbólicos, significados, discursos y prácticas, todos en relación dinámica con la cotidianidad.

Según plantea Álvaro (1995) para Moscovici, las representaciones sociales no son solo productos mentales, sino construcciones simbólicas que se crean y recrean en el curso de las interacciones sociales; las representaciones sociales pueden ser entonces comprendidas como maneras específicas de entender la realidad. (Soto y Vasco, 2008 p. 9).

La mejor alternativa con la que cuenta una comunidad para incluir a sus miembros es el reconocimiento del universo de significados que producen (Moscovici, 1979), es decir, que para los entes gubernamentales, es fundamental conocer las interpretaciones que los jóvenes barristas hacen de su localidad y de sí mismos, de la misma manera, una forma de establecer puentes de comunicación entre estos dos sectores de la comunidad es brindar espacios de manifestación de sus maneras particulares de ver el mundo.

Es así como en las actividades desarrolladas para el proyecto, se indagó por lo que específicamente significa ser un joven barrista (encuesta semiestructurada), cuáles son sus rituales de grupo al interior de las barras, junto con los imaginarios de poder, liderazgo, pertenencia y territorio (observación participante y taller realizado).

Ser joven, ¿una cuestión de buscar, obtener y mantener el "poder"?

Al acercarse a la realidad de los jóvenes barristas se debe tener en cuenta que sus imaginarios sobre la juventud obedecen a sus experiencias personales con relación al mundo de los adultos; son construcciones complejas 
que no se desechan por la lógica, sino que se valoran e interpretan como formas de "entender" y dar significado al mundo en el que se vive.

Un aspecto es fundamental: para quienes participaron en las actividades, ser joven es una cuestión de "hacerse sentir", en términos de abrirse lugar en una comunidad donde los adultos ponen las reglas, las rompen, pero al mismo tiempo, exigen de la población juvenil su acatamiento y, en un sentido más profundo, su obediencia. Lo anterior parece describir al mismo tiempo la relación entre los jóvenes y los adultos, lo cual será explorado con mayor profundidad más adelante.

Como hallazgo se encontraron los imaginarios expresados - brevemente- a continuación, se reitera en que deben contemplarse con apertura y actitud interpretativa, teniendo en cuenta el contexto en el cual son construidos:

- Los jóvenes y los adultos viven en "mundos" separados aunque comparten cotidianamente los mismos espacios físicos (casa, escuela, calle, parque, comercio).

- La brecha entre jóvenes y adultos involucra la comunicación y el lenguaje (cada cual tiene su forma de hacerse entender), las creencias y cosmogonías (cada cual busca explicar a su manera lo que le rodea), las normas (los adultos las establecen y esperan que sean cumplidas por los jóvenes, quienes a su vez establecen las suyas propias).

- Ser joven es permanecer en un mundo donde los adultos (familia, escuela, gobierno) tienen la capacidad de establecer y exigir el cumplimiento de normas.

- Ser joven es tener la posibilidad de disfrutar del mundo de los adultos sin serlo, es decir, sin compartir sus niveles de responsabilidad.

- Ser joven es, en ocasiones, ser objeto de discriminación e indiferencia por parte de los adultos.

- Ser joven es reconocer que se tiene la capacidad y posibilidad de ser otro al que determinan los adultos, por ende y a diferencia de los niños, trasgredir lo establecido por los adultos como apropiado y establecerse así mismo con una identidad propia.
- Ser joven es acercarse a otros jóvenes antes que a los adultos, establecer lazos afectivos donde la similitud está dada por la condición de ser jóvenes.

- Si para los adultos es válido relacionarse con los jóvenes por medio de la imposición, la fuerza o la indiferencia, para los jóvenes es igualmente válido relacionarse con los adultos bajo las mismas condiciones, argumentando incomprensión mutua o negación de sus realidades.

Estos imaginarios no son construcciones exclusivas de los jóvenes barristas de la localidad, pues reflejan un necesidad que tampoco es nueva en las comunidades y sus miembros; para la psicología del desarrollo es clásica la propuesta de un joven que confronta sus creencias infantiles (impuestas por los adultos durante el proceso de crianza) como una forma válida y necesaria para construirse a sí mismo como adulto en su sociedad (Adler, 1953). Entonces, la percepción desfavorable del mundo de los adultos por parte de los jóvenes es el resultado de sus experiencias durante la crianza.

Es así como se interpreta que la juventud para los jóvenes barristas es el momento de su vida en la cual pueden tomar el poder que no se les concedía durante su infancia, ejerciéndolo en todas las dimensiones posibles: acceso a espacios y actividades, disponibilidad de recursos y autonomía en sus propias decisiones.

El poder y la motivación presentes en los jóvenes barristas

Los hallazgos, adicionalmente, relacionan el ser barristas con atribuciones propias de "poder", "pasión", "autenticidad", “compromiso", "pertenencia”, "reconocimiento y prestigio", e identifican como principales marcos de referencia y sentido el grupo y el equipo de fútbol al cual siguen, es decir, las atribuciones anteriormente mencionadas giran en torno a estos dos. Al respecto, los aportes teóricos de la psicología humanista y uno de sus grandes exponentes, Abraham Maslow (1970), afirman que todos los seres humanos tienden a satisfacer sus necesidades en un orden específico: primero, se encuentran las necesidades fisiológicas; en segundo lugar, las relacionadas con la seguridad y la estabilidad; en tercer lugar, la pertenencia y el afecto; en cuarto, la autoestima y el autoconcepto para, finalmente, llegar a la autorrealización; lo anterior en un proceso dinámico que no cesa a lo largo de todo el ciclo vital. 
Así, entonces, al revisar las respuestas de los jóvenes barristas, se encuentra que el grupo y el equipo, son los contextos interno y externo en los que encuentran satisfacción a todas estas necesidades: la barra los acoge cuando no encuentran otro espacio, les permite sentirse seguros, respetados y parte activa del colectivo, asumiendo como propios los logros del equipo al que siguen y personales las afrentas hacia su grupo, finalmente, se desbordan de emocionalidad en actividades relacionadas con ser barrista.

Como fenómeno social, estos grupos de jóvenes merecen todo el reconocimiento, pues les garantiza un lugar y un sentido en el mundo y en la vida, así como los recursos para afrontar las exigencias de un entorno competitivo y en este caso adverso, es en la barra donde descubren el afecto por un equipo que, aunque no los reconozca con nombre propio ni les agradezca los frutos de su pasión, les permite sentirse capaces, en un contexto donde las oportunidades son reducidas, lo que fortalece procesos de autoestima y autorreconocimiento.

Es posible afirmar, entonces, que ante todo lo que les ofrece la barra y los miembros que la conforman, las normativas sociales, las reglas sociales y las estructuras comunitarias formales, pierden legitimidad y relevancia para cada uno de ellos, ya que en ningún lugar, sino en su grupo, encuentran el sentido que buscan como seres humanos.

Cabe destacar que lo anterior es una interpretación que no legitima ni avala actividades de intolerancia o violencia, busca solo la descripción de los significados de ser barrista; entonces, la pregunta para todos los actores sociales, sería ¿cómo generar espacios de gratificación, expresión y participación para estos jóvenes en concordancia con las normas básicas de convivencia?

Al respecto de las características identitarias de las diferentes barras y tras la recolección de información escrita de los jóvenes en estos grupos, se evidencian aspectos como la legitimación de actividades como el consumo de sustancias, así como la construcción de una simbología gráfica compleja, cuya interpretación está limitada a los conocedores, por ende, a los miembros del grupo. En un sentido más amplio, este es un rasgo común a todos los grupos humanos, la necesidad de diferenciarse y generar límites con el exterior, influye en la creación de lenguajes y medios de comunicarse internamente.

\section{Identidad, liderazgo y territorio}

Como colectivo humano, el fenómeno de las barras futboleras es permeado por aspectos generales y ampliamente estudiados por la sociología y la psicología social: la generación de una estructura o jerarquía interna, la administración de la autoridad y el poder, la delimitación territorial y la construcción de simbolismos identitarios, así como la transacción de estos en la interacción de los individuos son algunos de ellos y materia principal de este punto.

En cuanto a las estructuras jerárquicas, se encuentra que las barras futboleras en esta localidad no son diferentes a las localizadas en otros sectores de la capital colombiana u otras naciones occidentales; se establecen a partir de vínculos de amistad por semejanza entre individuos con proximidad geográfica compartiendo la realidad de su localidad y una cotidianidad similar. La adherencia de nuevos miembros a estos obedece por convocatoria o referenciación social, en torno a un tópico base: la afición a un equipo de fútbol determinado.

Es entonces cuando la individualidad se ve influenciada por las características del grupo, situación que adquiere mayor fuerza durante el final de la infancia y el inicio de la adolescencia, y una serie de gustos, intereses, estilos y "formas de ser" son asumidas por el individuo, quien a su vez, las transforma y las regresa al grupo en un ciclo de retroalimentación cotidiano.

Así como lo plantean las teorías sociales, "los grupos se hacen más complejos al enriquecerse su identidad y avanzar hacia la formalidad" (Myers, 1997), por lo que las barras formalizan también sus procesos de admisión e iniciación de nuevos miembros por medio de valoraciones, pruebas y aprobaciones por parte de sus líderes. Durante la realización de las actividades se encontró un nivel de formalización básico, donde los jóvenes pertenecían a su grupo como seguidores o como líderes, sin que se identificara mayor especialización en los roles.

Lo anterior nos lleva al tema del poder, la autoridad y el liderazgo al interior de la barra: es el líder, también conocido entre los jóvenes como el "capo", quien asume las funciones de orientación, establecimiento y logro de objetivos del grupo, así como la aprobación de rasgos identitarios y admisión de nuevos miembros.

Como se mencionó, estos grupos se encuentran en un nivel elemental de formalización, las funciones del líder no se encuentran formalizadas o de manera explícita, 
por lo que son asumidas por el "capo" por iniciativa y evaluación o regulación del grupo, de igual manera se encontró como rasgo común que la edad cronológica y nivel experiencial de los líderes eran mayores a las de sus seguidores. En síntesis, se es líder en la barra cuando se cuenta con la edad, voluntad y condiciones para serlo y mantenerse en esta posición.

La administración de las funciones como líder acude al poder investido, nuevamente de manera implícita, en ellos, basadas en el desempeño de las actividades propias de la barra y los momentos más significativos de agremiación: asistencia a eventos deportivos, reuniones sociales y actividades como delimitación de territorios.

Las barras en esta localidad mantienen la visibilización del grupo y sus simbologías como una forma de delimitación territorial. Si bien la proximidad habitacional genera la agremiación de los jóvenes barristas, es el contexto territorial inmediato en el cual conviven los jóvenes el que se convierte en su espacio colectivo; el mismo que debe obtenerse al competir con otros grupos o demostrarse presencia por medio de expresiones públicas como los mencionados anteriormente. Sin embargo, esta simbología gráfica se complejiza cada vez más al entender que, si la barra futbolera se gesta en torno a los equipos de este deporte, no hay tantos equipos como barras, por lo que cada grupo debe definirse de tal manera que, en asuntos como el territorio, se tenga claridad aun entre aficionados del mismo equipo.

\section{Familia e institucionalidad}

En términos generales, el joven barrista sostiene una percepción negativa sobre las estructuras institucionales. Dado que en gran parte de las encuestas aplicadas se mencionaron aspectos como la corrupción y la indiferencia que los jóvenes le atribuyen al gobierno local, junto con la segregación y persecución de las autoridades policivas, es como si ser joven, habitante de Bosa y miembro de una barra se convirtieran en un estigma social; relacionadas con el miedo, la inseguridad, y la discriminación con las que sus vecinos reaccionan ante sus medios de expresión y reunión. Al respecto, explica Esteban Rodríguez (2008):

Sabemos que la juventud es pasto verde para los lugares comunes, un terreno fértil para el sentido común, campo plagado de estigmas y estereotipos. Hablar de la juventud, sobre todo de la juventud de los barrios marginales, es hacer referencia a las mil y una formas en las que esta fue estereotipada. La mayoría de las veces, esos estereotipos son negativos, es decir, categorías que descalifican y vuelven sospechosa a la juventud. (s. p.).

Para los círculos más ortodoxos de la sociología y la psicología, la familia, como célula básica de la sociedad, es el primer contexto relacional con el cual el individuo establece las bases para su interacción con el entorno ya que satisface las necesidades básicas del sujeto en crecimiento.

Por lo anterior se considera una preocupación y responsabilidad elemental de los entes gubernamentales asegurar las condiciones para que la familia cumpla con las funciones de protección de sus miembros en términos de derechos y deberes.

Por otro lado, una perspectiva sistémico-compleja de la familia asegura que esta es un conjunto dinámico de partes en relación constantemente permeado por las condiciones del entorno (Minuchin y Fishman, 1981), lo anterior resulta más útil a la hora de interpretar las realidades de los jóvenes barristas, ya que una comprensión de sus contextos y antecedentes familiares muestran una red compleja de múltiples influencias, donde los derechos y deberes, así como la autoridad, son solo una mínima parte en la construcción de su vida cotidiana. Es frecuente encontrar jóvenes que cumplen las funciones de sus padres, asumiendo el cuidado de sus hermanos menores; madres que realizan la función de padres y madres simultáneamente, padres jóvenes que delegan el cuidado de sus hijos a los abuelos u otros familiares, familias compuestas por varias generaciones y distintos padres.

Por lo mismo, la realidad del barrista permite otras formas de ser familia, fuera de la teoría y la academia: durante la realización del taller, por ejemplo, se evidenció la prelación que las imágenes femeninas como la madre tienen para los jóvenes, mientras que lo masculino en términos de autoridad parece ser objeto de resistencia. No es casual, entonces, que cuando se habla de relaciones negativas con imágenes de autoridad como la policía, los docentes o los gobernantes de la localidad, se reaccione con rechazo.

En este sentido, grupos sociales como las barras asumen las funciones propias del contexto familiar, brindan afecto, pertenencia y seguridad al joven barrista, la barra se ubica como alternativa inmediata de compensación para el joven que busca satisfacer sus necesidades sociales y afectivas. 
La violencia resulta no ser un fenómeno exclusivo de las barras como aseguran los imaginarios de la comunidad, tanto como el resultado de un contexto orientado a las prácticas de violencia que permea sistemas tan relevantes como la familia, es decir, el hecho de ser barrista no implica el estar involucrado en actividades violentas.

En muchas ocasiones estas "tribus urbanas" son objeto de similar visión y tratamiento social e institucional que las pandillas o parches. De igual manera, quienes se agrupan en su identidad con un equipo de fútbol y realizan actividades de acompañamiento, en ocasiones violentas, las llamadas "barras bravas", las cuales no pueden clasificarse como grupos delincuenciales o predelincuenciales, así en determinadas ocasiones, algunos de sus miembros puedan protagonizar acciones vandálicas o agresiones personales. (Secretaría de Gobierno Distrital, 2007, p.28).

\section{Barras, jóvenes barristas e instituciones}

Dentro de sus múltiples manifestaciones, las instituciones son la formalización del orden y el poder dentro de las comunidades; a ellas se asigna y confía el manejo de recursos, establecimiento de políticas, formación y reproducción cultural, así como el desarrollo de acciones que tiendan al mejoramiento constante de las condiciones de vida de los habitantes, en ellas reposa la promoción y defensa de los derechos, también la exigencia de los deberes como ciudadanos.

En el caso que nos ocupa, las instituciones buscan regular la presencia de los jóvenes en la comunidad, acatando las responsabilidades a ellas encomendadas; desde esas funciones legitiman medidas de control que inevitablemente amplían la brecha entre el mundo de los adultos, con su deber ser, y el de los jóvenes, con sus realidades inmediatas, a través relaciones de resistencia y desconfianza mutuas.

Desde una perspectiva sistémica, la relación de las barras juveniles con las instituciones de la localidad de Bosa sigue las mismas pautas de cualquier grupo social dentro de la comunidad: durante la revisión documental, por ejemplo, se encontró la indiferencia y rechazo que los entes gubernamentales tienen hacia las necesidades de los habitantes centradas en la falta de oportunidades, la inequidad y el trato discriminatorio.

No es de sorprender, entonces, que los jóvenes inmersos en estas condiciones a lo largo de su crianza respondan con desconfianza, desinterés, rechazo y resistencia ante las estructuras establecidas; estas parecen respuestas válidas ante un orden que no los incluye y los percibe como riesgo social.

Al afrontar estas condiciones, más que control se necesitan estrategias de inclusión, a partir del reconocimiento de las distintas realidades, que disminuyan los prejuicios mutuos (barristas-instituciones) y orientadas a la construcción de espacios de encuentro y concertación, como es el caso de las recientemente celebradas "mesas futboleras", primer intento de acercamiento de las distintas barras.

\section{PROYECCIÓN Y PERSPECTIVAS}

Después del proceso de contextualización y caracterización del joven barrista, podemos proyectar unas líneas de acción que dinamicen la interacción con él, en segunda instancia, que permita a la localidad y sus instituciones comprender mejor a esta población e intervenir de una manera más afectiva sobre la realidad que acontece.

En este sentido, se plantean tres aspectos fundamentales en las acciones a desarrollar: 1. Generar procesos de investigación, 2. Procesos de información y 3. Procesos de intervención; que actúen de manera permanente, armónica y sistémica. Además de estas acciones, se debe:

- Plantear estrategias para el reconocimiento de todos los sujetos que intervienen en el desarrollo de la comunidad y propiciar los espacios de encuentro, en donde en un clima armónico se dé la oportunidad para la manifestación de la diversidad.

- Transformar la mirada (negativa) que se tiene sobre el joven y sobre el joven barrista en la localidad.

- Indagar a mayor profundidad sobre la población "objeto" de estudio, para lo cual la investigación social con sus posibilidades de etnografía, estudios de caso e historia de vida podrían aportar información significativa al respecto.

- Mejorar los procesos de seguimiento, cualificación e intervención de las dinámicas del joven barrista.

- Integrar a través del diálogo la concertación y la participación, al grueso de la comunidad y al joven barrista 
- Fortalecer las políticas de juventudes en la localidad.

- Plantear las opciones de acción social y política para la atención de las prioridades así como la interpretación de la población participante, a partir de la conformación del Observatorio de Juventud Barrista.

\section{CONCLUSIONES}

El informe hace evidente la poca información que se tiene con respecto a la juventud barrista desde ópticas diversas, positivas, incluyentes, que den apertura al reconocimiento del otro y a generar procesos de participación verdadera en la comunidad; por lo mismo, se hace necesario generar procesos de investigación social que amplíen el conocimiento que se tiene al respecto.

La pobreza y el desempleo o la falta de oportunidades son factores fundamentales que deben ser tratados a la hora de intentar tramitar las diferencias entre la comunidad y las agrupaciones juveniles, las agrupaciones juveniles, al igual que sus manifestaciones, se constituyen como proceso de resistencia, comunicación, visibilización y expresión de las formas particulares de ver el mundo.

Existe una relación dialéctica entre las posturas y manifestaciones juveniles frente a la imposición del mundo de los adultos, como una manera de asignar significados a una realidad que le es ajena.

El lenguaje y la comunicación se convierten en elementos fundamentales de identidad, expresión de creencias y cosmogonías que delimitan los roles generacionales y sociales, en este proceso el joven se reconoce como individuo, simultáneamente reconoce y comparte características que los hace "grupo".

Se evidencia que las relaciones adulto-joven, instituciónjoven, contienen una fuerte carga negativa desde procesos de imposición, fuerza, indiferencia, inequidad, trato discriminatorio y desconfianza; como referente interno, los jóvenes asocian el hecho de ser barristas con atribuciones propias de poder, pasión, autenticidad, compromiso, pertenencia, reconocimiento y prestigio.
La barra como territorio social se constituye en una forma alternativa de familia, en donde se descubren afectos y se fortalece la autoestima y el autorreconocimiento, en últimas, donde compensa sus necesidades sociales y afectivas y le posibilita asignar sentido a la vida.

La violencia no es un fenómeno exclusivo de la barras, más bien, esta es producto de un contexto adverso, orientado a las prácticas de violencia que permea todas las estructuras sociales; al afrontar estas condiciones, más que control se necesitan estrategias de inclusión, a partir del reconocimiento de las distintas realidades, disminuyendo los prejuicios mutuos (barristas-instituciones), estrategias orientadas a la construcción de espacios de encuentro y concertación.

Por otra parte, la barra y los jóvenes barristas han resignificado el sentido de la práctica deportiva, el espectáculo desbordó los límites del estadio y el tiempo de los partidos para trasladarse al barrio y a la vida cotidiana.

Se hace fundamental un observatorio del joven barrista como un espacio de encuentro entre diferentes realidades, que proponga alternativas de conciliación, emprendimiento, formación y oportunidades, y estrategias de comprensión del joven barrista desde otras ópticas y mediante categorías alternativas.

La violencia se encuentra en el entorno, extendidas por fenómenos como el tráfico y consumo de estupefacientes, el delito como fuente de ingreso, vandalismo, trámite del conflicto de forma violenta, antecedentes familiares de violencia y maltrato.

La participación como mecanismo de activación social, a generarse en un observatorio, permitirá acercar a los jóvenes barristas y la comunidad en general a formas alternas de desarrollo, observar formas de intervención de la población enfatizadas en el asistencialismo, y asumir una postura de reconocimiento y empoderamiento del joven como sujeto de derecho.

Es necesaria la creación y consolidación de estructuras sistémicas (de interacción y retroalimentación permanentes) para el conocimiento, reconocimiento e intervención de los jóvenes barristas en la localidad.

No se evidencian procesos institucionales de recolección de datos claros, fiables, actuales y públicos sobre la condición de la juventud barrista en la localidad. 


\section{REFERENCIAS}

Adler, A. (1953). Práctica y teoría de la psicología del individuo. Buenos Aires: Paidós.

Alcaldía Mayor de Bogotá (2000). Plan de Ordenamiento Territorial (РОT). Decreto 619.

Álvaro, J. (1995). Psicología social: perspectivas teóricas y metodológicas. Madrid: Siglo XXI Editores.

Aponte, D., Pinzón, D., y Vargas, A. (2009). Barras de fútbol, juventud y conflictos, mapeo en la localidad de Kennedy (Bogotá). Bogotá: CERAC.

Ávila, S. (2008). Laterales, análisis de las barras bravas. Revista Virtual Universidad Católica del Norte, (25), 1-22.

Cámara de Comercio de Bogotá (2001). Observatorio social de Bogotá, Indicadores básicos de calidad de vida y desarrollo humano. No 7, recuperado en: http://bibliotecadigital.ccb.org.co/bitstream/ handle/11520/2119/869_2004_10_25_9_47_7_ obser_social_7.pdf?sequence $=1$

Clavijo, J. (2004). Estudio de las barras de fútbol de Bogotá, los comandos azules. Universitas Humanística Universidad Javeriana, 58(58), 42-59.

Gómez, G. (s. f.). Explosividad emotiva, barras bravas en Bogotá. Bogotá: ASCIENTE.

Minuchin, S., y Fishman, H. (1981). Family theraphy techniques. Cambridge (Mass.): Harvard University Press (Trad. Castellana: Técnicas de terapia familiar, Barcelona, Paidós Ibérica, 1988).
Moscovici, S. (1979). El psicoanálisis, su imagen y su público. Buenos Aires: Hwemel.

Myers, M. (1997). Qualitative research in information systems. Mis Quarterly, 21(2).

Rodríguez, E. (2008). El joven en la mira. En marcha de la asociación judicial bonaerense (AJB). Asociación Judicial Bonaerense. Tomado de www.ajb.org.ar

Secretaría de Gobierno Distrital- Fundación Ciudad Humana - Fundación Servicio Colombiano de Desarrollo Social, (2007). Marco teórico conflictividad, seguridad, convivencia y gobernabilidad en Bogotá, Análisis de factores de conflictividad que afectan la gobernabilidad, la seguridad y la convivencia en Bogotá" Recuperado en: http://www.sercoldes.org. co/images/pdf/conflictividad.pdf

Soto, N., y Vasco, C. (2008). Representaciones sociales y discapacidad. Hologramática-Facultad de Ciencias Sociales, 8(1), 3-22.

Vélez, J. (2005). La violencia en el espectáculo del fútbol, una realidad en el nuevo contexto colombiano, $\mathrm{X}$ Congreso Mundial de Historia del Deporte, Universidad Pablo de Olvide, Sevilla. España. Recuperado en: http://www.cafyd.com/HistDeporte/htm/pdf/4-19. pdf 24 de octubre de 2010. 